Journal of Al-Azhar University Engineering Sector

Vol.16, No. 59, April 2021, 252-263

\title{
BORONIZING MITIGATE FAILURE MECHANISMS WITH EXTENDED LIFE IN OIL/GAS STEEL PIPING UNDER ACOUSTIC INDUCED VIBRATION (AIV)
}

\author{
Marwa Mohamed Saeed ${ }^{1}$, Mohamed A. Bayoumi², and Bakr M. Rabeeh ${ }^{3}$ \\ ${ }^{1}$ Al-Azhar University, Faculty Of Engineering, Department Of Mechanical Engineering. \\ marwa.msalama@hotmail.com \\ ${ }^{2}$ Al Azhar University, Faculty Of Engineering, Department Of Mechanical Engineering. \\ Mohammadbayoumy.18@azhar.edu.eg \\ ${ }^{3}$ German University in Cairo (GUC), Faculty of Engineering and materials Science, Department Of \\ Engineering and Materials Science. bakr.rabeh@guc.edu.eg
}

\begin{abstract}
.
Oil and gas piping systems suffer from acoustically induced vibration, AIV, that end with hearing losses and consuming personnel's lives. However, Leak-Before-Break (LBB) methodology was developed to mitigate failure, the primary piping systems exhibit an extremely low probability of rupture (xLPR). For understanding of piping failure mechanisms under AIV, 3-point bending tests are conducted to study structural integrity in oil/gas piping (ASTM A333 Carbon Steel GR.6 Seamless). Besides, for ultra-fast surface hardening and strengthening, a non-traditional powder pack boronizing technique is introduced at $950^{\circ} \mathrm{C}$ for 10 and 30 minutes. Mechanical characterization as well as microstructural analysis are conducted for continuous and incremental bending tests. In addition, FE modeling, ANSYS, is conducted on actual "case study" of oil/gas piping to study the changes in dynamic characteristics for both as-received (AR) and boronized steel Under AIV(173 dB). Failure mechanisms is established in AR sample with clear banding and early localized microplasticity at 0.2 flexural stress $\left(\sigma_{f}\right)$. Void coalescence induce crack initiation at $0.3 \sigma_{\text {f. }}$ Crack propagation (at $0.5 \sigma_{f}$ ), crack evolution (at $0.7 \sigma_{f}$ ) and catastrophic failure are captured. Boronizing with the diffusion of Boron into the outer surface dominate functional-graded materials (FGM), with surface and bulk hardening. Surface hardening via boronizing mitigate fracture mechanisms with no clear micro-plasticity, but with clear twinning and banding elimination. In addition, to investigate the sustainability of piping and the effect of boronizing, under AIV, FE modeling is introduced with two different steel piping systems (AR with strength $580 \mathrm{MPa}$, and boronized steel with strength $1390 \mathrm{MPa}$ ). Failure mitigation is introduced with the increase of endurance limit as well as increase of piping life.
\end{abstract}

Key Words: Acoustic Induced Vibration (AIV), Banding, Boronizing, FE Modeling, FGM, Failure Mechanisms, LBB, Life Extension, Mitigation of Failure, Twinning, xLPR. 


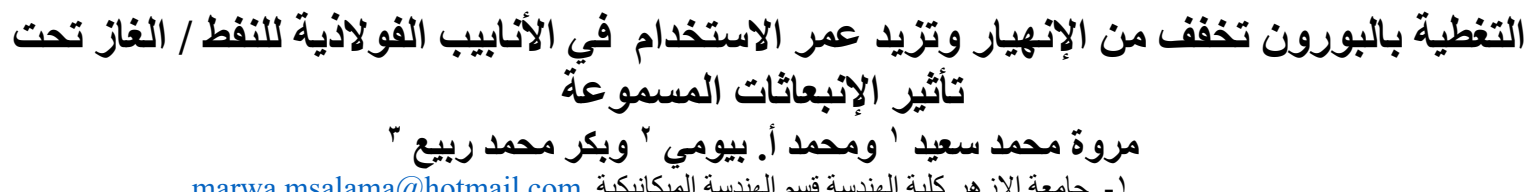

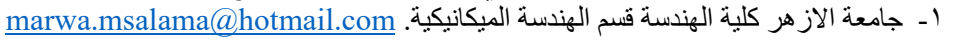

Mohammadbayoumy.18@azhar.edu.eg جامعة الأزهر ـ كلية الهندسة ـ قسم الهندسة الميكانيكية. 2

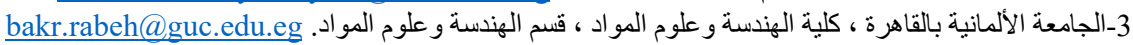

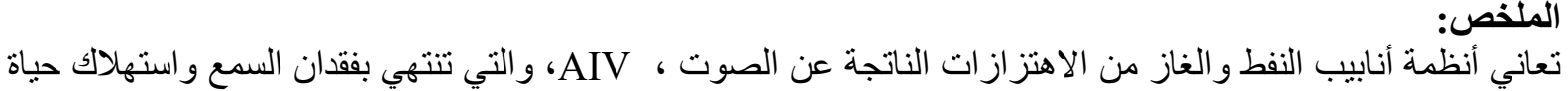

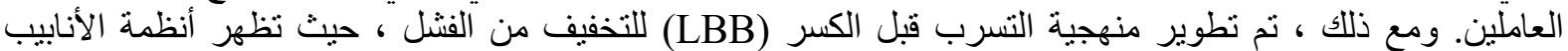

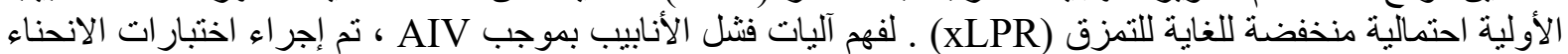

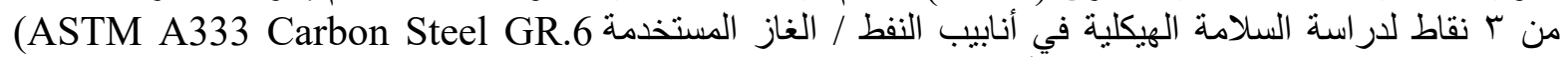
( . Seamless)

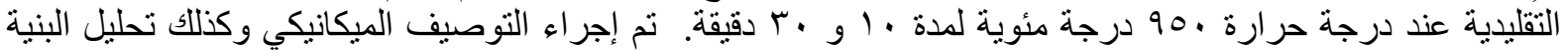

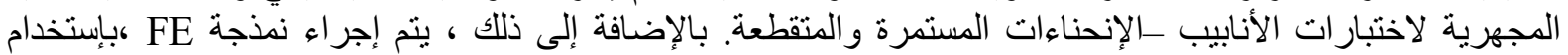
ANSYS

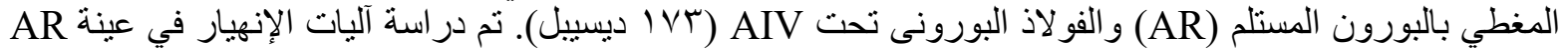

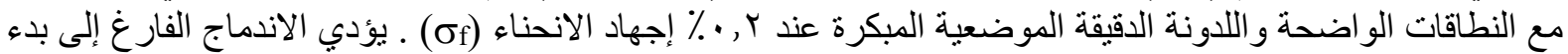

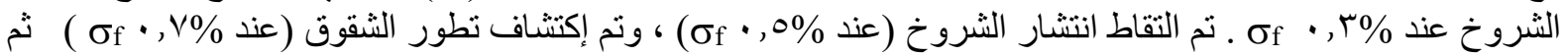

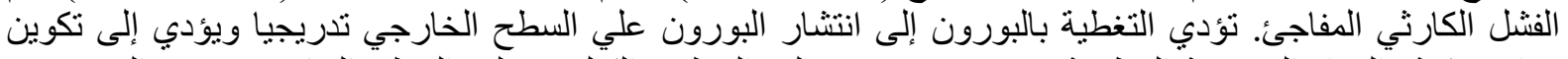

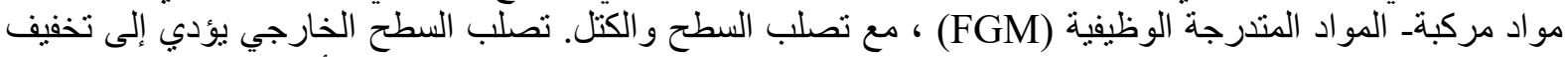

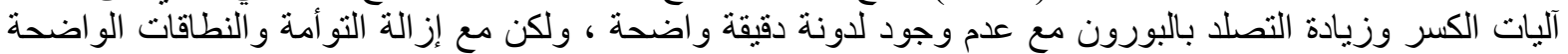

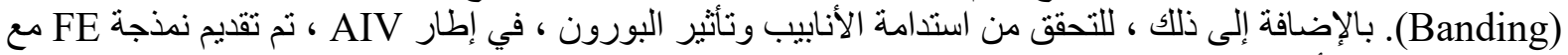

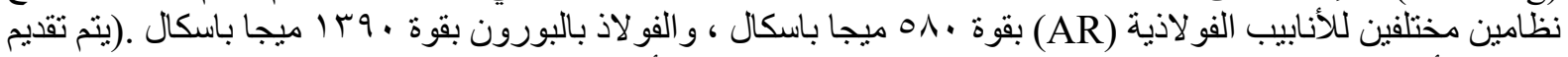

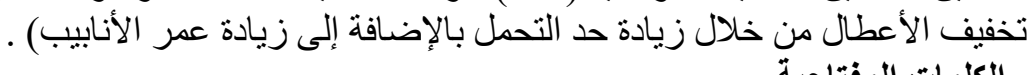

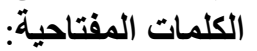

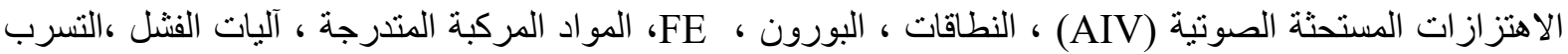

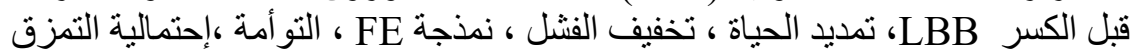

\section{INTRODUCTION}

Most probably, in petroleum and natural gas transportation pipelines, Vibrations are one of the main factors of causing fatigue failure. Excessive vibrations can lead to fatigue failure, they occur when a mechanical natural frequency of the piping system is excited by some pulsations or by a mechanical acoustic source [1-4]. Acoustic induced vibration, AIV, in piping may induce vibration shapes usually involve lateral vibrations and wall radial circumferential vibrations which can lead to fatigue failure. The pipelines are exposed to different kinds of severe vibrations such as the vibration which is due to large sound power level generated by the pressure relieving valves or blow down valves, in which high levels of high frequency acoustical energy is generated downstream the valve [5-6]. The sound power level is a function of the pressure drop across the device, the upstream pressure, the mass flow through it, the molecular weight and the temperature. This energy propagates downstream of the valve where the resulting vibration causes failure due to fatigue, sometimes in just hours of operation, this phenomenon occurs and cause a great human losses and economical losses [7-9]. However, The Leak-Before-Break (LBB) methodology, as described in NRC Standard Review Plan (SRP), was developed to mitigate failure. A General Design Criteria (GDC) requires that primary piping systems exhibit an extremely low probability of rupture (xLPR) in order to exclude dynamic effects associated with postulated primary pipe ruptures [10-11]. Many researchers carried out fatigue experiments using the austenitic SUS316 steel plates by repeated bending. Striations were observed with fine slip bands [12-13]. Powder-Pack Boronizing as a nontraditional method is introduced and investigated at different temperatures [14-16]. Besides, powder-pack boriding process on low-carbon stainless steel was carried out and investigated [17]. Moreover, the kinetics of the Boride Layers Obtained on AISI 1018 Steel by Considering the Amount of Matter Involved 
[18]. However, Fracture mechanisms need more investigation and recommended new solution to mitigate failure and extend lives. Three different objectives are considered; 1 study the kinetic of damage mechanisms in actual "case study" piping system (ASTM A333 Carbon Steel GR.6 Seamless). 2- Mitigation of failure and ultra-fast surface hardening and strengthening of steel piping via non-traditional powder pack boronizing. 3- Micro mechanical modeling via ANSYS to conduct structural integrity and life prediction for two different materials, the as-received sample and the boronized samples under AIV. Mechanical characterization via tensile testing and 3-point testing (continuous and repeated) along with microstructural analysis via optical and scanning electron microscopy are investigated.

\section{EXPERIMENTAL WORK}

Boronizing, a non-traditional powder pack technique, is introduced at $950^{\circ} \mathrm{C}$ for 10 and 30 minutes in an induction furnace. A mixture of boric acid and borax in an equal weight is packed around steel samples ( 2 sets), heated in an induction furnace till $950^{\circ} \mathrm{C}$, with two different holding times (10 and 30 minute), then air cooled. Micro hardness test, Vickers hardness, is conducted on the AR samples and boronized samples (from the sample surface to the bulk sample center). Boronizing reveals the ultra-fast surface hardening from $126 \mathrm{HV}$ (AR) to $1792 \mathrm{HV}$ (Boronized sample at 30 minute. In addition, it reveals strengthening mechanisms that increase flexural strength $\left(\sigma_{f}\right)$, from $580 \mathrm{MPa}$ to $1214 \mathrm{MPa}$ for 10 minute, and to $1390 \mathrm{MPa}$ for 30 minute boronized samples. The kinetic of boronizing also reveals different fracture mechanisms. No clear localized micro-plasticity is captured at the outer hardened surface that hinder slipping and mitigate the cracks. Besides, twinning and elimination of banding from $100 \%$ parallel to the surface (AR sample) to be $100 \%$ perpendicular to the surface that is captured from $0.5 \sigma_{\mathrm{f}}$. As received samples of the actual steel pipe (ASTM A333 Carbon Steel GR.6 Seamless) are sliced into two different test (continuous and incremental) for two different group (AR and Boronized).

\section{MODELING AND SIMULATION}

Modeling and simulation is also established via ANSYS to conduct a real design "case study" in oil/gas piping system under sound power levels $173 \mathrm{~dB}$. Sound acoustic source (pressure regulating valve (PRV)) is also considered as the root cause of failure at distance 3 meter duct length (of diameter $=219 \mathrm{~mm}$ ) to the header of diameter $610 \mathrm{~mm}$. To investigate the sustainability of piping under different boundary conditions, micromechanical modeling is illustrated for the AR samples with strength of $580 \mathrm{MPa}$, and boronized steel with strength of $1390 \mathrm{MPa})$. Stress-Number of cycle to failure (S-N) is introduced and compared to reveal the importance of ultra-fast surface hardening and strengthening to mitigate failure and enhance endurance limit.

\section{RESULTS AND DISCUSSIONS}

Simultaneously repeated 3 -point bending tests is conducted on sample $(3 \times 15 \times 60 \mathrm{~mm})$ and presented in Figure 1 (a) continuously, and (b) repeated bending. The continuously repeated bending reveals clear softening and reduction of flexural strength $\left(\sigma_{f}\right)$ with reduction of corresponding strain; from $580 \mathrm{MPa}$, at $22 \%$ strain (Fig. 1a- test 1) to $220 \mathrm{MPa}$, at $2.0 \%$ strain (Fig. 1b-test 9). An incremental 3-point tests are conducted to reveal microstructural changes and fracture mechanisms via optical microscopy (Fig. 2 a-b) and SEM (Fig. 3 to Fig. 8). Fig. 2 presents optical microscopy with clear banding of ferritic-pearlitic structure, that is parallel to sample surface (due to post forming processing) of the as-received steel sample (a) at the sample surface, low magnification (10X), and (b) at the sample bulk center, high magnification (20X).

Figure 3 presents SEM of the early detection of localized micro-plasticity at $0.2 \sigma_{\mathrm{f}}$ localized micro-plasticity demonstrates itself at the outer sample surface as; grain boundary flow (3 $\mu \mathrm{m}$ ) and presistent slip bands, PSB, of $5 \mu \mathrm{m}$ length, (Fig. 3a) low magnification, and (Fig.

3b) high magnification. Figure 4 presents SEM of Localized micro-plasticity that 
demonstrate itself as beach marks, striations, and void initiation, in the AR outer sample surface, at $0.3 \sigma_{f}(a)$ low magnification, and (b) high magnification. Figure 5 presents SEM of Crack initiation via void coalescence in-received steel sample at $0.3 \sigma_{f}(a)$ at equal spacing from the outer sample surface, (b) voids coalescence that induce crack initiation (high mag.). Figure 6 presents SEM of crack propagation in as-received steel sample, aligned parallel to the outer surface (a) low mag. (at $0.4 \sigma_{\mathrm{f}}$ ), and (b) transgranular at $0.6 \sigma_{\mathrm{f}}$. Figure 7 presents SEM of crack propagation in as-received steel sample, outer sample (a) at equal spacing from the outer surface at $0.7 \sigma_{f}$ (low mag.), and (b) Trans granular at $0.9 \sigma_{f}$ (high mag.). Figure 8 presenta catastrophic failure via SEM of as-received steel sample (a) two different zones; fatigue and rupture (low mag.), (b) beach marks and striations (high mag.) at $\sigma_{\mathrm{f}}$.

Boronized 3-point bending samples at $950^{\circ} \mathrm{C}$ for 10 and 30 minute are established and presented. Figure 9 presents stress strain diagram of 3-point bending tests of samples boronized at $950^{\circ} \mathrm{C}$ for (a) 10 minute, and (b) 30 minute holding time. Boronizing at 950 ${ }^{\circ} \mathrm{C}$ increases flexural stress from $580 \mathrm{MPa}$ (AR sample) to $1214 \mathrm{MPa}$ at 10 minutes and to $1390 \mathrm{MPa}$ at 30 minutes. Besides, clear increase in strain from $22 \%$ strain (of AR) to $40 \%$ strain (boronized at 10 and 30 minute) with clear increase of yielding stress as well as Young's modulus. Figure 10 presents depth of surface hardening via boronizing of steel A333 Grade 6 at $950^{\circ} \mathrm{C}$ for (a) 10 minute $(\sim 15 \mu \mathrm{m})$, and (b) for 30 minute holding time ( 65 $\mu \mathrm{m})$. Micro hardness, Vickers hardness, tests are conducted at the sample surface, different spaced depth $(40 \mu \mathrm{m})$ from the surface, and a comparison is presented for as received (Table 1) and boronized at 30 minute (Table 2). Boronizing reveals not only a clear increase of the depth of hardened layer (Fig. 10) but also increase of micro hardness from $126 \mathrm{HV}$ (AR) to $1792 \mathrm{HV}$ (Boronized sample at 30 minute), that dominate the clear increase of flexural strength (Fig. 10). After incremental bending tests, each sample is cut at the bending area, along its length (20 $\mathrm{mm}$ length), and sample edge $(3 \mathrm{~mm})$ is prepared (mounted, ground, polished and etched) to monitor fracture mechanisms. Boronizing induces transitionally function-graded- materials (FGM), from very hard (ceramic) surface to more ductile bulk matrix (steel). Figure 11. Optical microscopy of boronized sample under repeated 3-point bending; (a) banding parallel to outer surface at $0.1 \sigma_{\mathrm{f}}$, mag. 10X, (b) the commencement of twinning at $0.5 \sigma_{\mathrm{f}}$ mag. 20X (c) more twining with oriented banding perpendicular to outer surface at $0.6 \sigma_{\mathrm{f}}$, mag 20X. A clear banding elimination is captured that is oriented parallel to the surface (AR) where the commencement of twinning is captured at $0.5 \sigma_{\mathrm{f}}$ with more elimination to be $100 \%$ perpendicular to the surface at $0.5 \sigma_{\mathrm{f}}$.

Scanning electron microscopy (SEM) of boronized, incremental 3-point bending samples are captured and presented at Figure 12 to Figure 16 . Figure 12 presents no clear microplasticity captured at the outer hardened sample surface at $0.2 \sigma_{f}(a)$ low magnification and (b) high magnification. On the contrary, localized micro-plasticity is captured in the bulk material, away from the hardened surface at $0.4 \sigma_{\mathrm{f}}$. Figure 13. SEM of Boronized steel sample at the bulk sample center at incremental $0.4 \sigma_{f}$ with (a) the commencement of twinning and banding elimination (b) clear micro-plasticity as grain boundary flow, voids and PSB (high mag). Figure 14. SEM of Boronized steel sample at the bulk sample center at incremental $0.6 \sigma_{f}$ with twinning and crack initiation at the bulk center (a) low magnification, and (b) high magnification. Figur15 presents crack propagation across PSB, via SEM of Boronized steel sample in the center of sample at incremental $0.7 \sigma_{f}(a)$ low mag. and (b) high mag. Crack propagation is captured at $0.9 \sigma_{f}$ in the sample center, however, no clear fracture capture at the outer hardened surface that presented in Figure 16. Figure 16. SEM of boronized sample: (a) Crack propagation at the sample center, with crack arrest in the outer surface, via SEM of boronized steel sample at incremental $0.9 \sigma_{f}$, (b) catastrophic ductile-dimpled fracture surface (high mag.).

Micro mechanical finite element modeling, ANSYS, established reveals the kinetic of boronizing that not only hinder plastic deformation in the outer hardened surface, but also hinder crack propagation, mitigate crack growth that extend service life. Stress-Number of cycle to failure (S-N curve) with boundary condition Fixed-fixed that induce circumferential deformation in both duct and header established to reveal the importance of boronizing. Figure 17 presents $\mathrm{S}-\mathrm{N}$ curve of as received design B1 and Boronized sample Via ANSYS. Boronizing not only extend life but also increase endurance limit $\sigma_{e}$ of as received from $\sigma_{e}$ $=157.5 \mathrm{MPa}$ at $6.1 \times 10^{5}$ cycles to $\sigma_{\mathrm{e}}$ of boronized $=405 \mathrm{MPa}$ at $9.23 \times 10^{6}$ cycles. 
BORONIZING MITIGATE FAILURE MECHANISMS WITH EXTENDED

LIFE IN OIL/GAS STEEL PIPING UNDER ACOUSTIC INDUCED VIBRATION (AIV)

Table 1 Hardness results of the as received Sample

\begin{tabular}{|l|l|}
\hline \multicolumn{2}{|l|}{ Hardness of uncoated Reference Sample } \\
\hline Reading 1 & $110 \mathrm{HV}$ \\
\hline Reading 2 & $120 \mathrm{HV}$ \\
\hline Reading 3 & $131 \mathrm{HV}$ \\
\hline Reading 4 & $143 \mathrm{HV}$ \\
\hline Average & $126 \mathrm{HV}$ \\
\hline
\end{tabular}

Table 2 Hardness Results of the Boronized sample at $950^{\circ} \mathrm{C}$ for 30 minute.

\begin{tabular}{|l|c|}
\hline \multicolumn{2}{|c|}{ Hardness Results of the boronized sample at $950^{\circ} \mathrm{C}$} \\
\hline Point A & $1792 \mathrm{HV}$ \\
\hline Point B & $1548 \mathrm{HV}$ \\
\hline Point C & $927 \mathrm{HV}$ \\
\hline Point D & $341 \mathrm{HV}$ \\
\hline
\end{tabular}

(a)

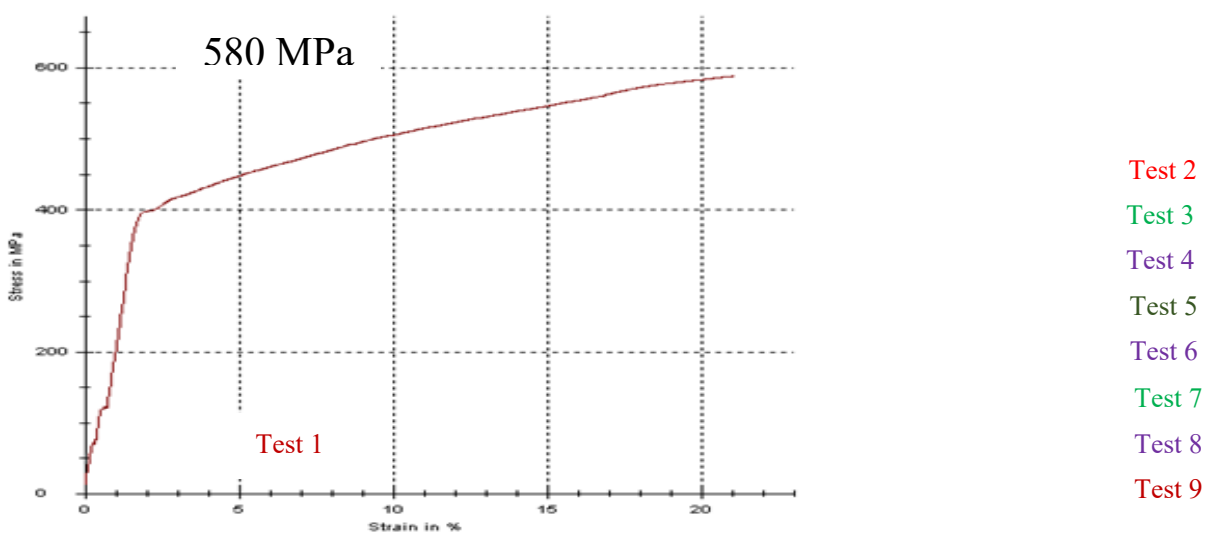

(b)

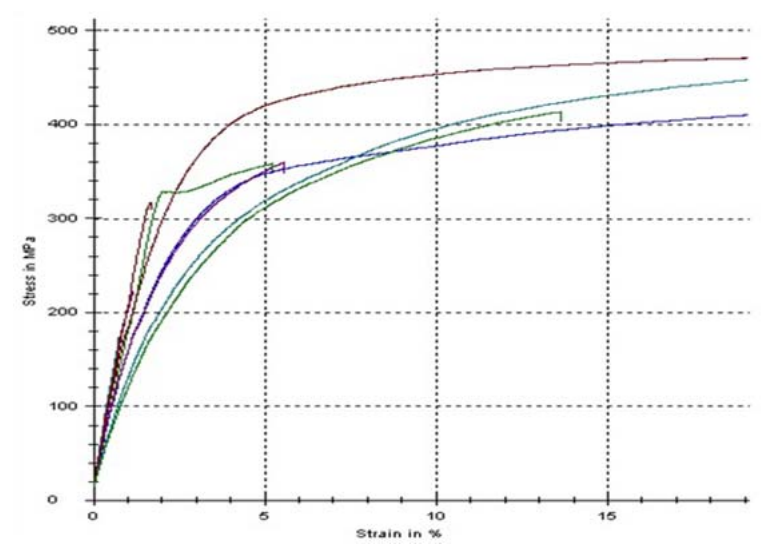

Fig 1. 3-point bending stress-strain diagram of AR; (a) single bending and (b) repeated bending test. 


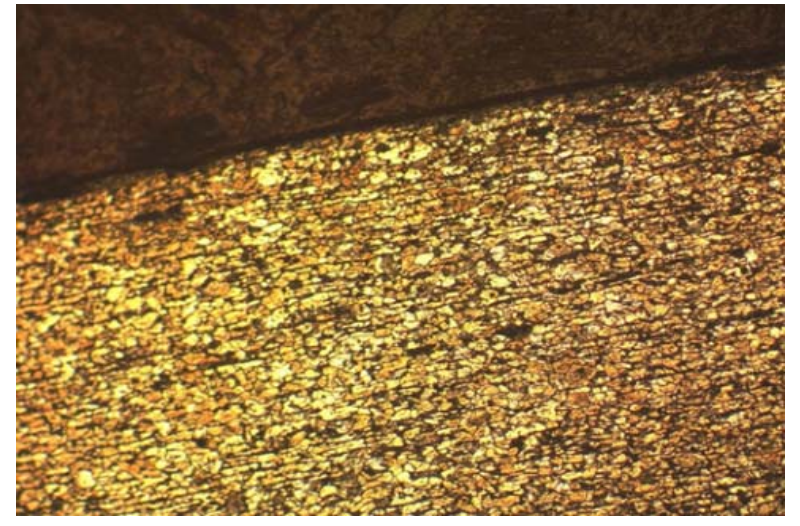

(a)

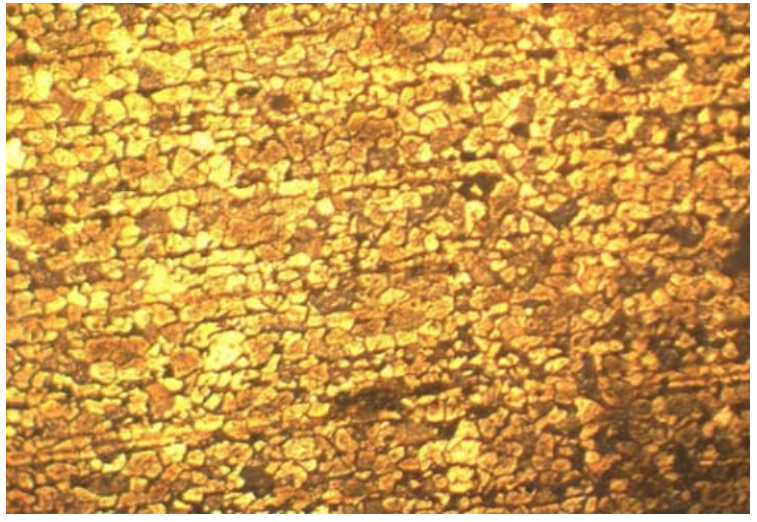

(b)

Figure 2. Banding, ferritic-pearlitic structure, via optical microscopy of as-received steel sample at (a) the surface (low mag. 10X), and (b) bulk center (high mag. 20X).

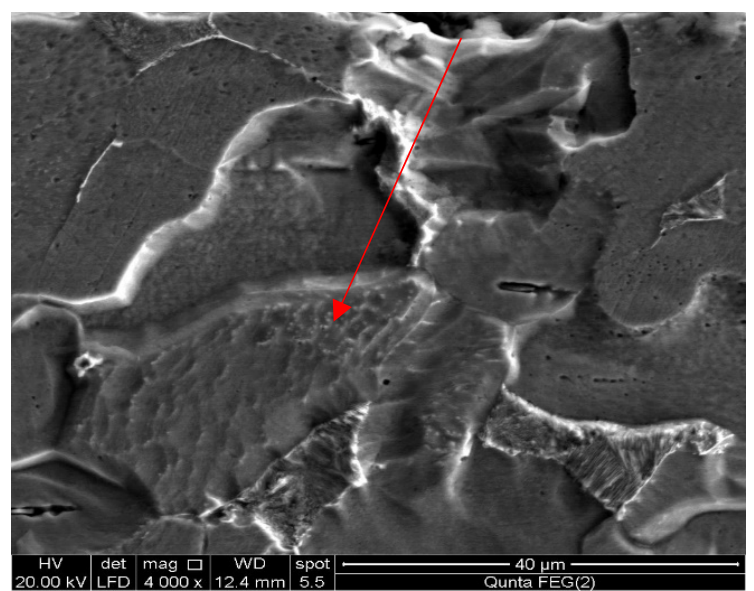

(a)

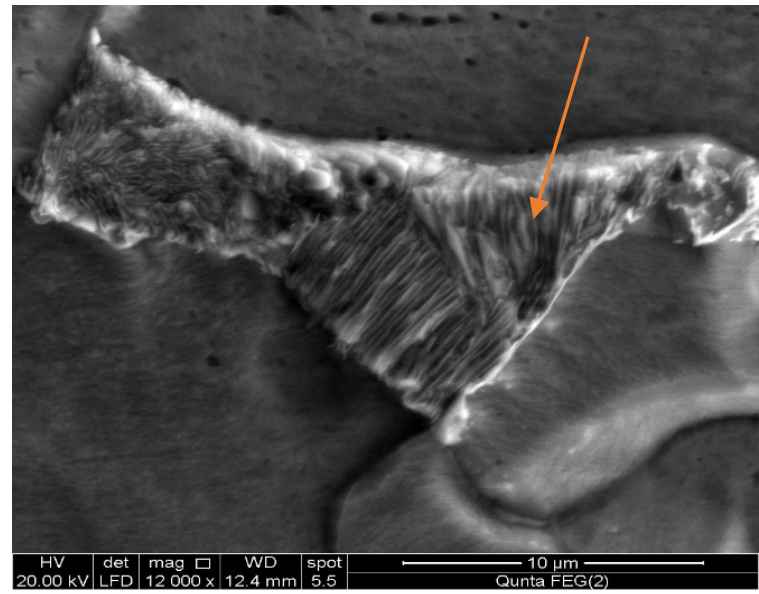

(b)

Figure 3. SEM of localized micro-plasticity, grain boundary flow and presistent slip bands (PSB), in asreceived steel sample, outer sample surface, at $0.2 \sigma_{f}(a)$ low magnification, and (b) high magnification.

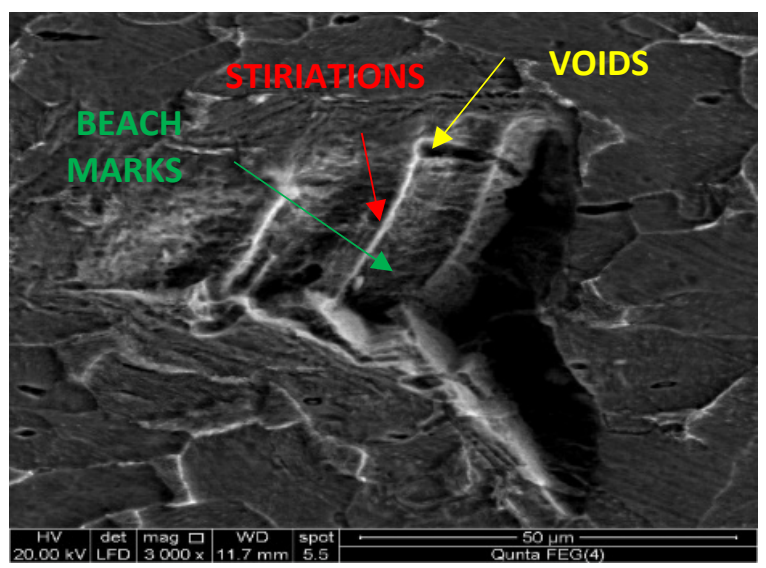

(a)

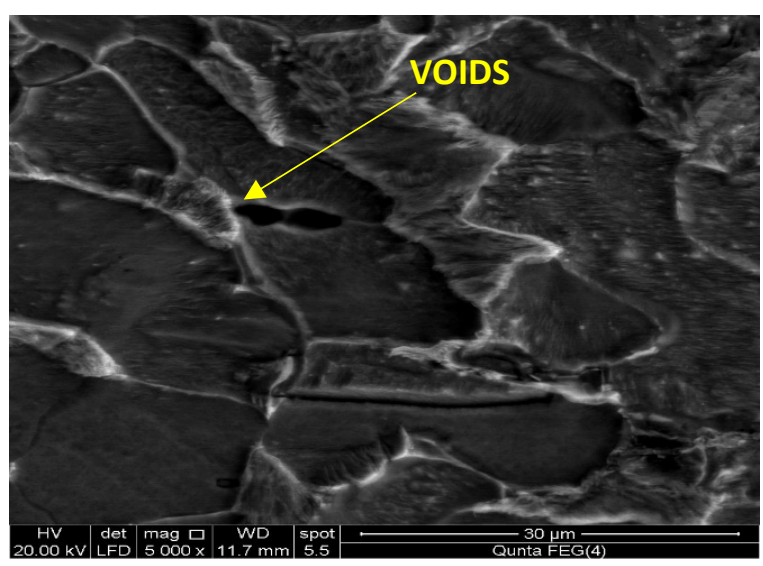

(b)

Figure 4. SEM of localized micro-plasticity, beach marks, striations, and void initiation, in as-received steel sample, outer sample surface, at $\mathbf{0 . 3} \sigma_{\mathrm{f}}$ (a) low magnification, and (b) high mag. 


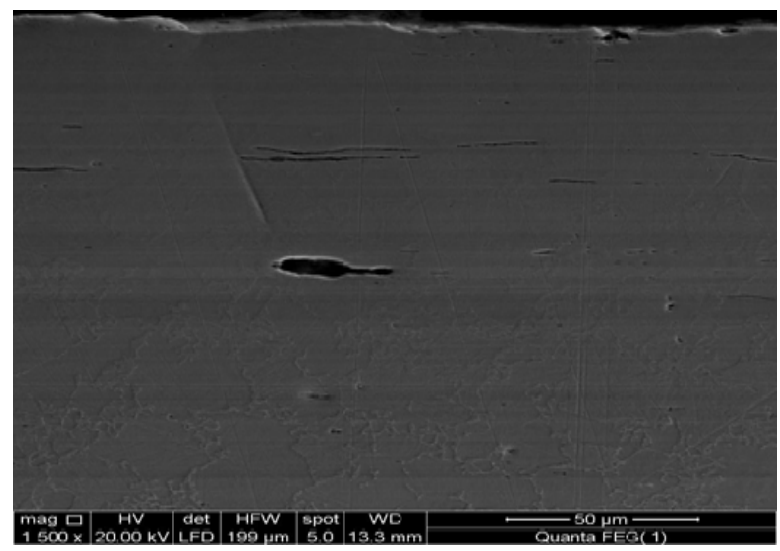

Figure 5. SEM of crack initiation via void coalescence in-received steel sample at $0.3 \sigma_{f}$. at the outer sample surface.

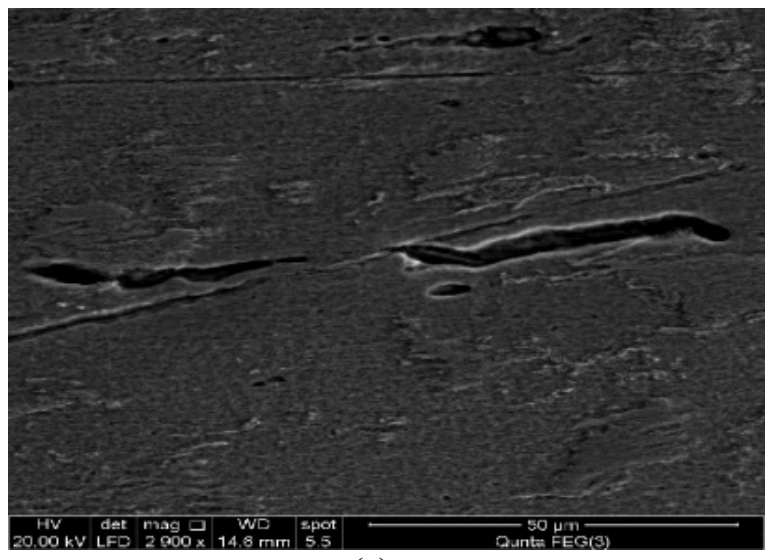

(a)

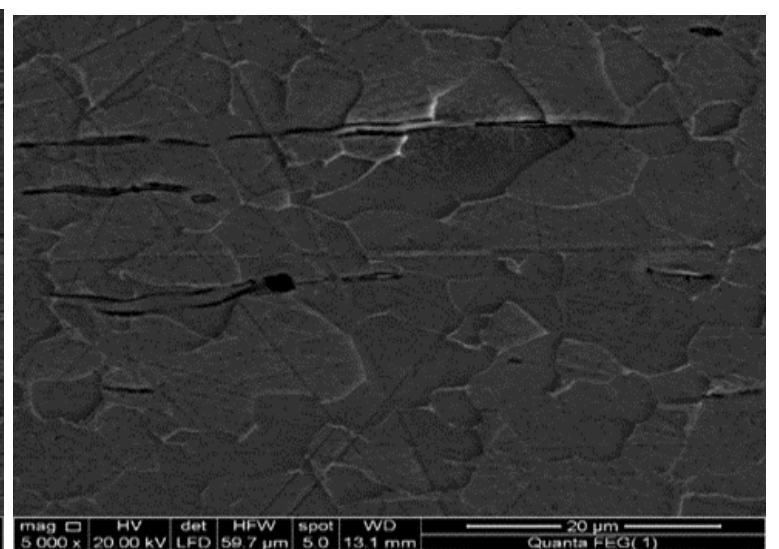

(b)

Figure 6. SEM of crack propagation in as-received steel sample, aligned parallel to the outer surface (a) low mag. (at $0.4 \sigma_{f}$ )., (b) transgranular at $0.6 \sigma_{f}$.

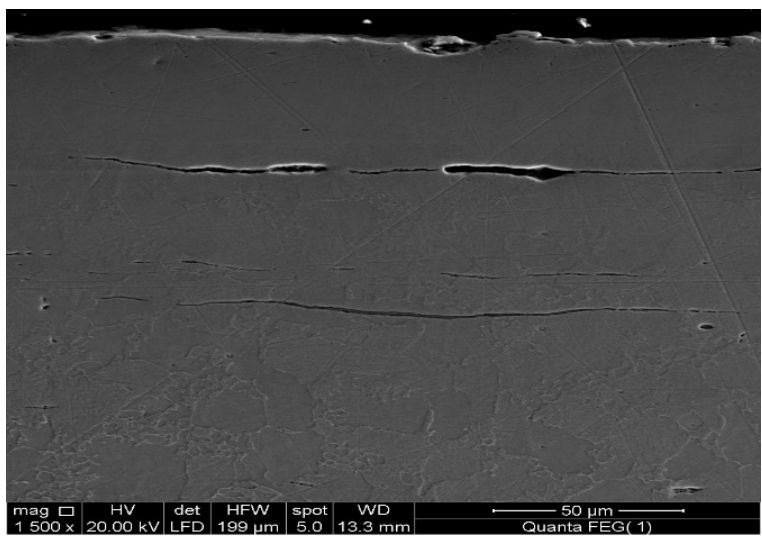

(a)

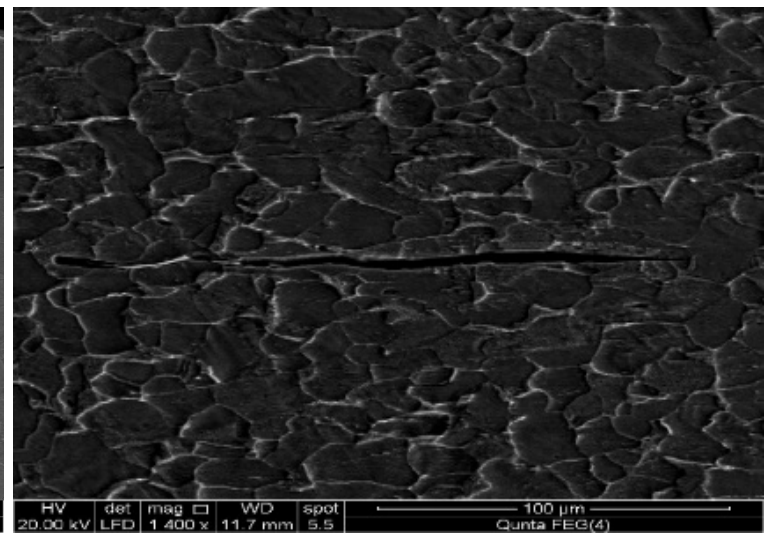

(b)

Figure 7. SEM of crack evolution in as-received steel sample, outer sample (a) low mag. surface at 0.7 $\sigma_{f}$, (b) Trans granular at $0.9 \sigma_{f}$. 

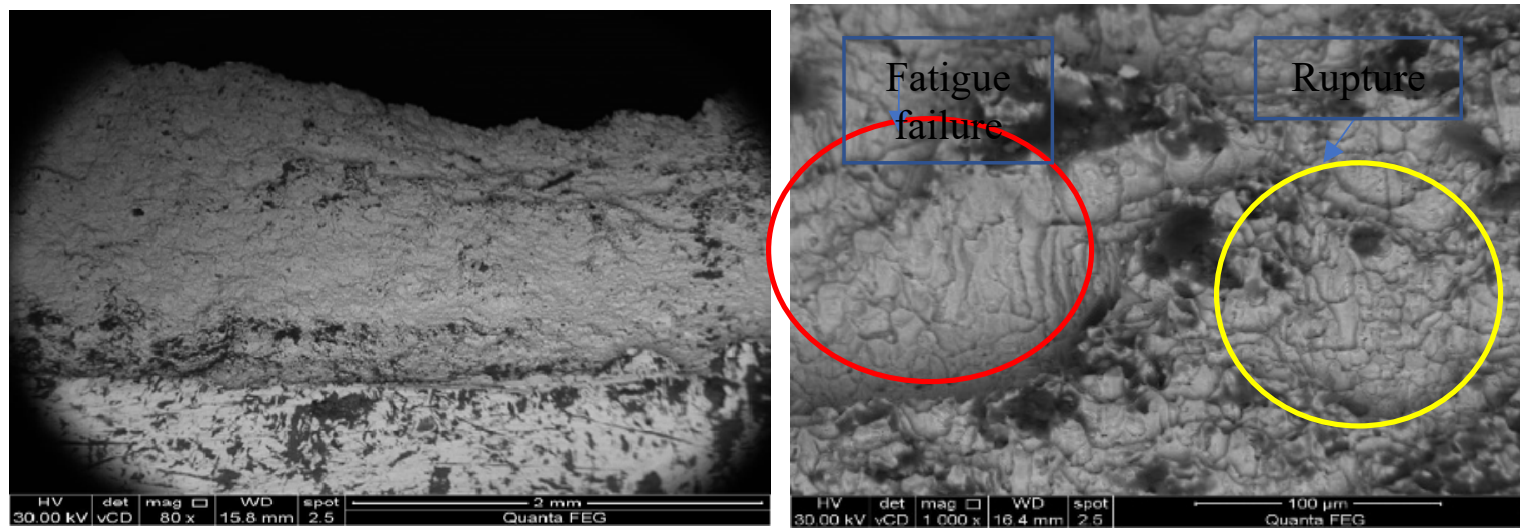

(a)

(b)

Figure 8. Catastrophic failure via SEM of as-received steel sample (a) two different zones; fatigue and rupture (low mag.), (b) beach marks and striations (high mag.) at $\sigma_{\mathrm{f} .}$

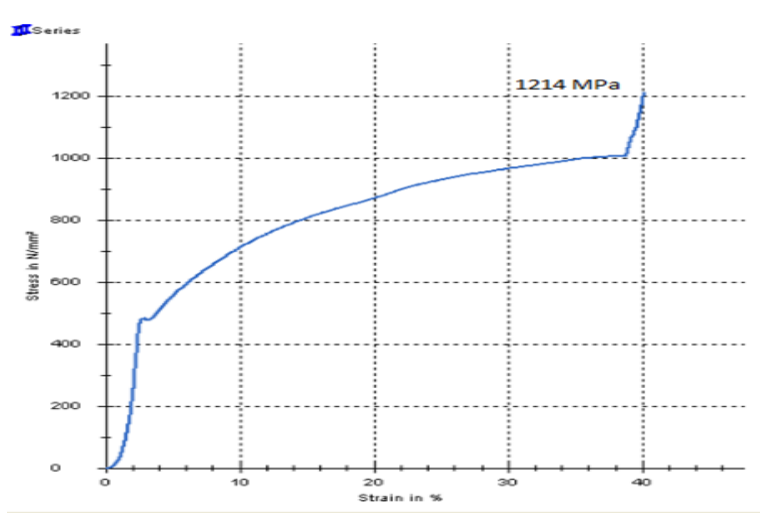

(a)

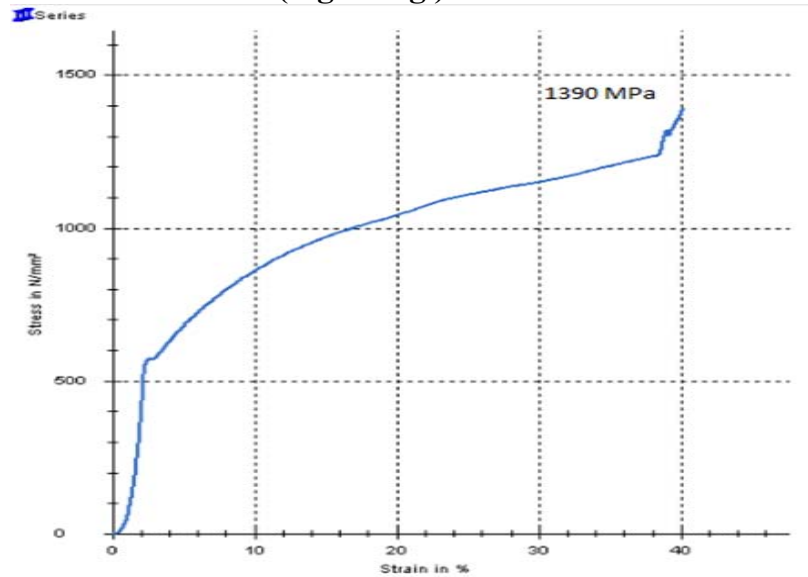

(b)

Figure 9. Stress-strain diagram of 3-point bending boronized samples at $950^{\circ} \mathrm{C}$ for (a) 10 minute, and (b) 30 minute holding time.

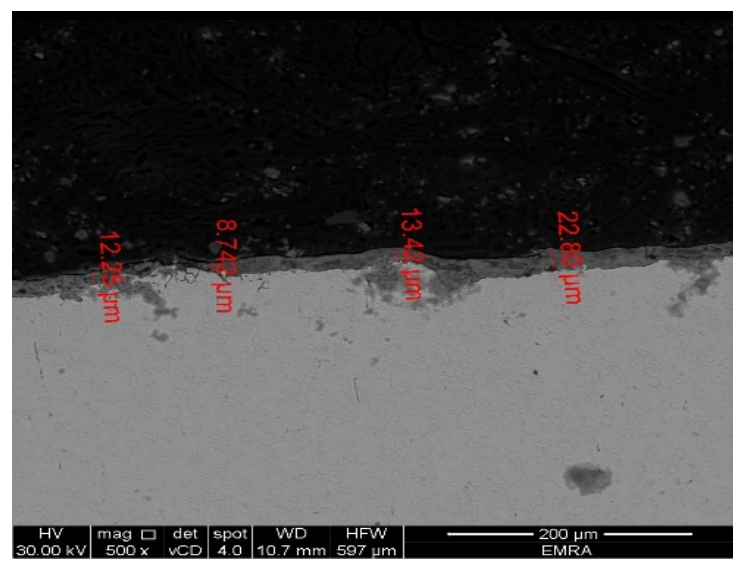

(a)

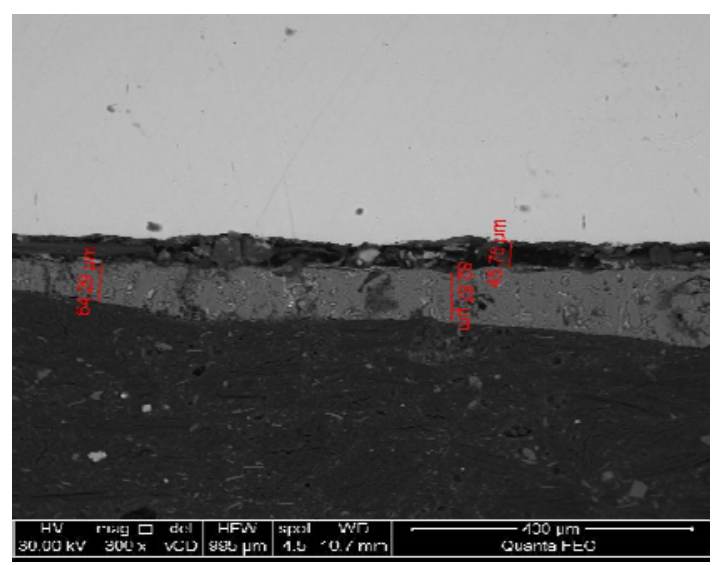

(b)

Figure 10. Depth of Boronizing and Surface hardening of steel A333 Grade 6 at $950^{\circ} \mathrm{C}$ for (a) 10 minute, and (b) for 30 minute holding time. 


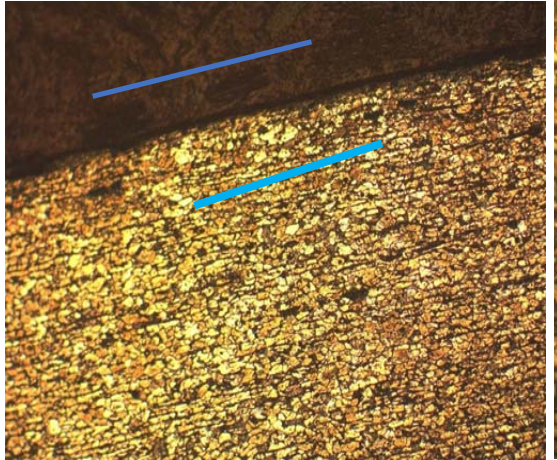

(a)

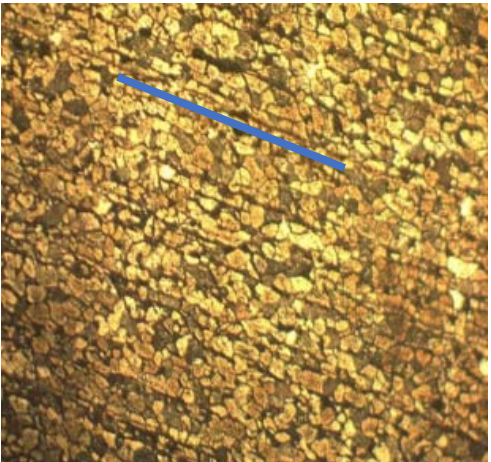

(b)

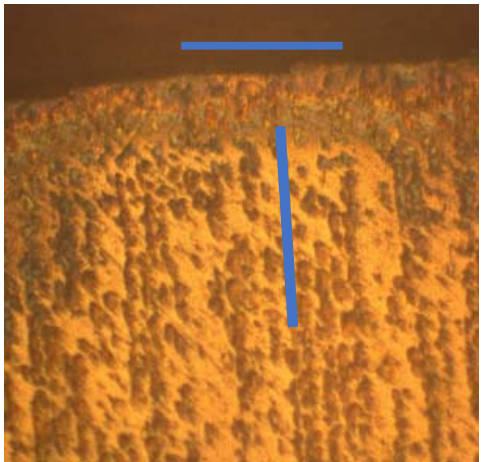

(c)

Figure 11. Optical microscopy of boronized sample under repeated 3-point bending; (a) banding parallel to outer surface at $0.1 \sigma_{\mathrm{f}}(\mathbf{1 0 X})$, (b) the commencement of twinning at $0.5 \sigma_{\mathrm{f}}(\mathbf{2 0 X})$, (c) more twining with oriented banding perpendicular to outer surface at $0.6 \sigma_{\mathrm{f}},(20 \mathrm{X})$.

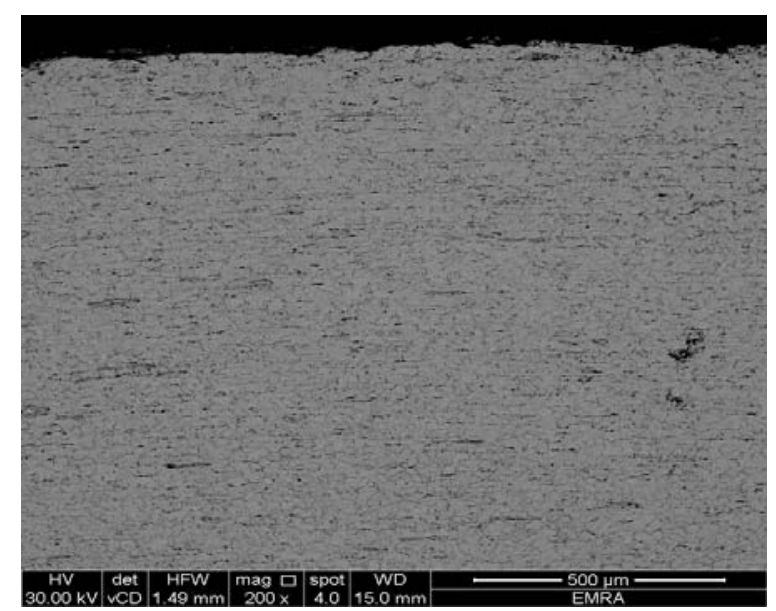

Figure 12. SEM of Boronized steel sample at the outer sample surface at incremental 0.2 of with no clear micro-plasticity.

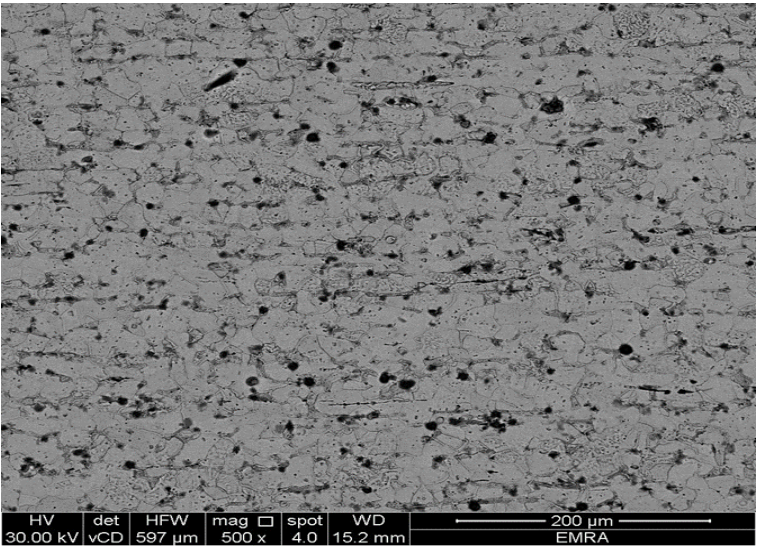

(a)

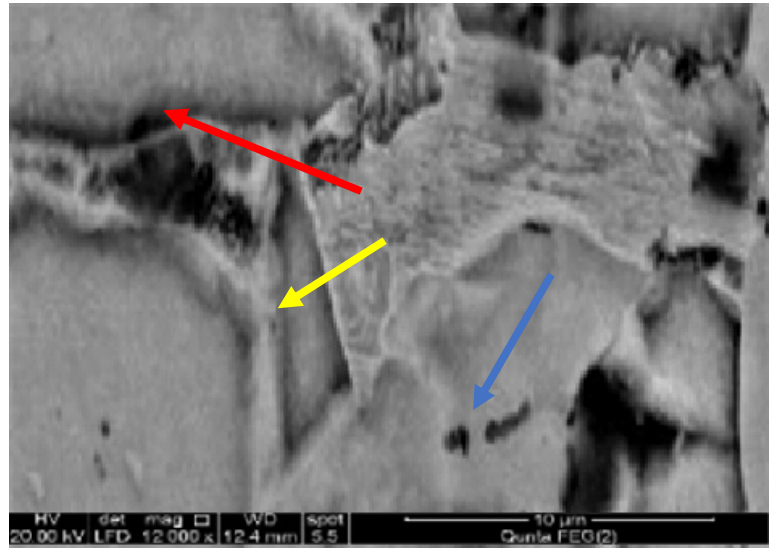

(b)

Figure 13. SEM of Boronized steel sample at the bulk sample center at incremental at 0.4 of with (a) the commencement of twinning and banding elimination, and (b) clear micro-plasticity as grain boundary flow, voids and PSB (high mag). 


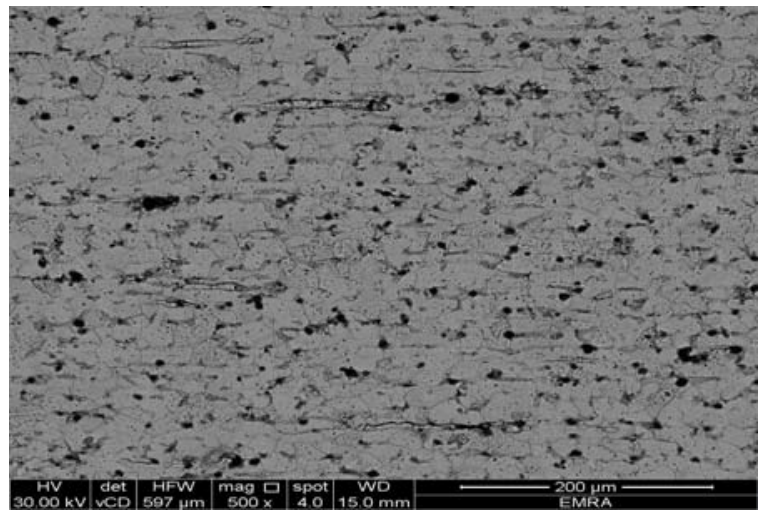

(a)

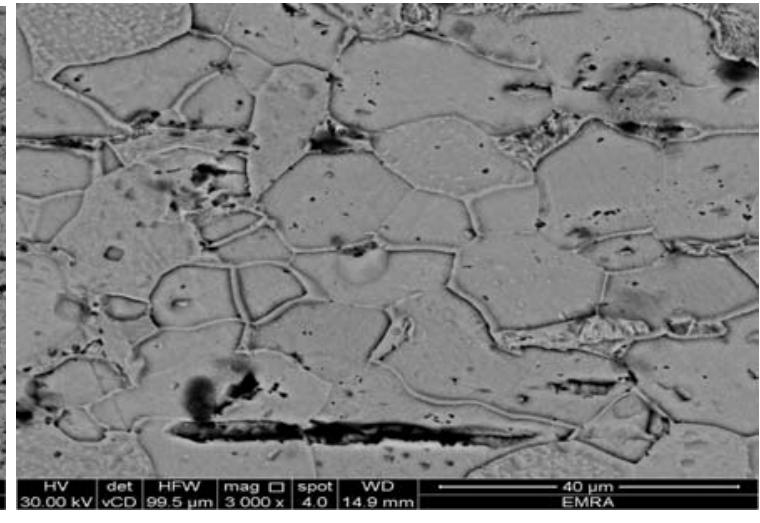

(b)

Figure 14. SEM of Boronized steel sample at the bulk sample center at incremental 0.6 of with twinning and crack initiation at the bulk center (a) low mag., and (b) high mag.

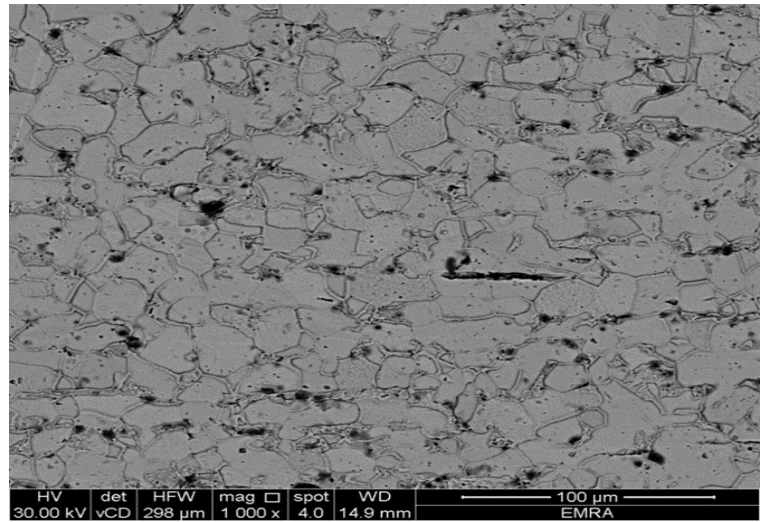

(a)

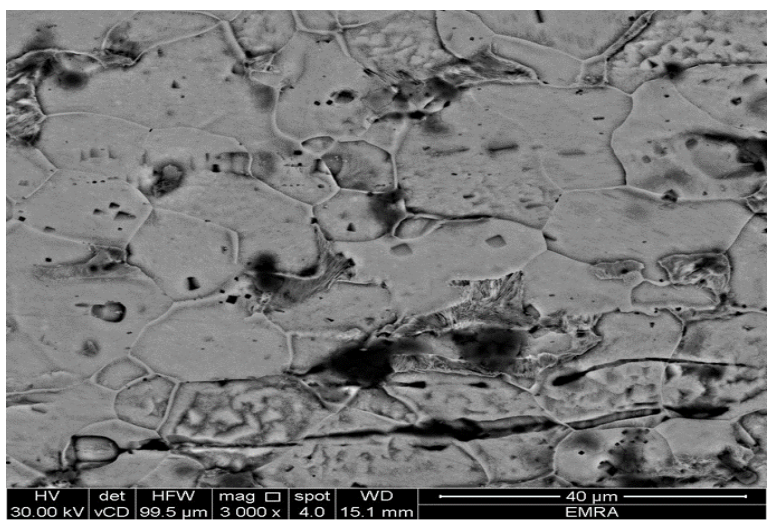

(b)

Figur15. Crack propagation across PSB, via scanning electron microscopy of Boronized steel sample at the center of sample at incremental 0.7 of (a) low mag. and (b) high mag.

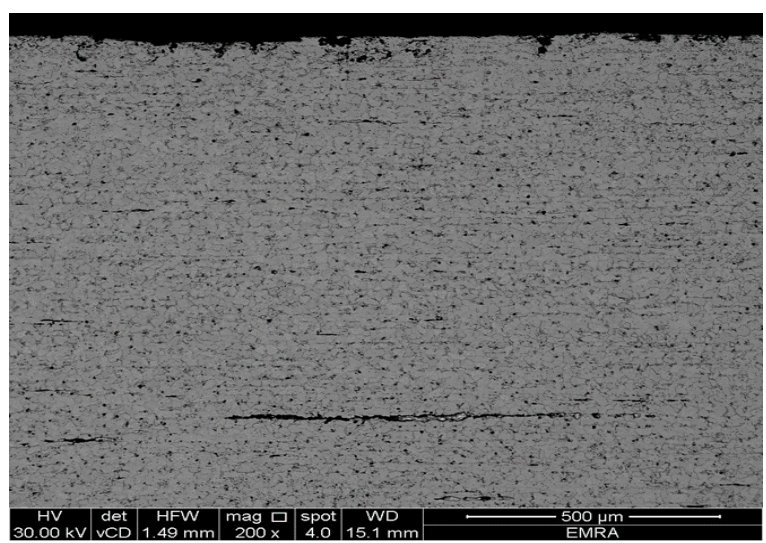

(a)

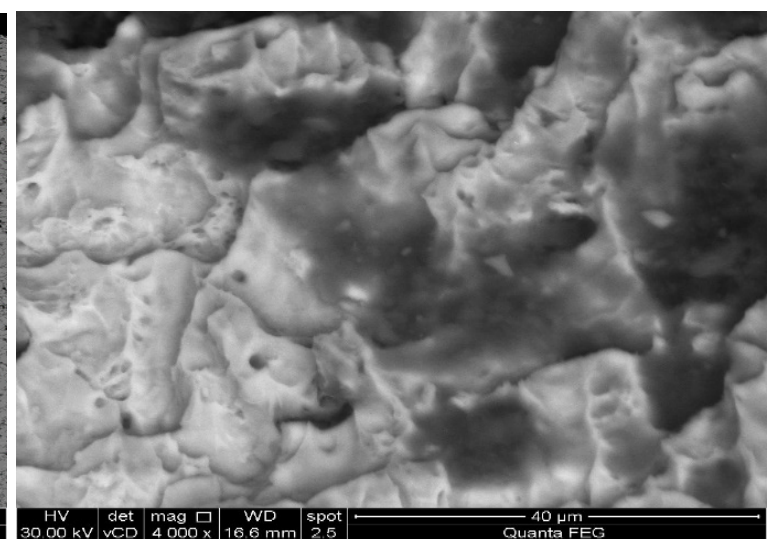

(b)

Figure 16. SEM of boronized sample: (a) Crack evolution at the sample center, with crack arrest in the outer surface, via scanning electron microscopy of Boronized steel sample at incremental 0.9 of , (b) catastrophic failure (high mag.). 


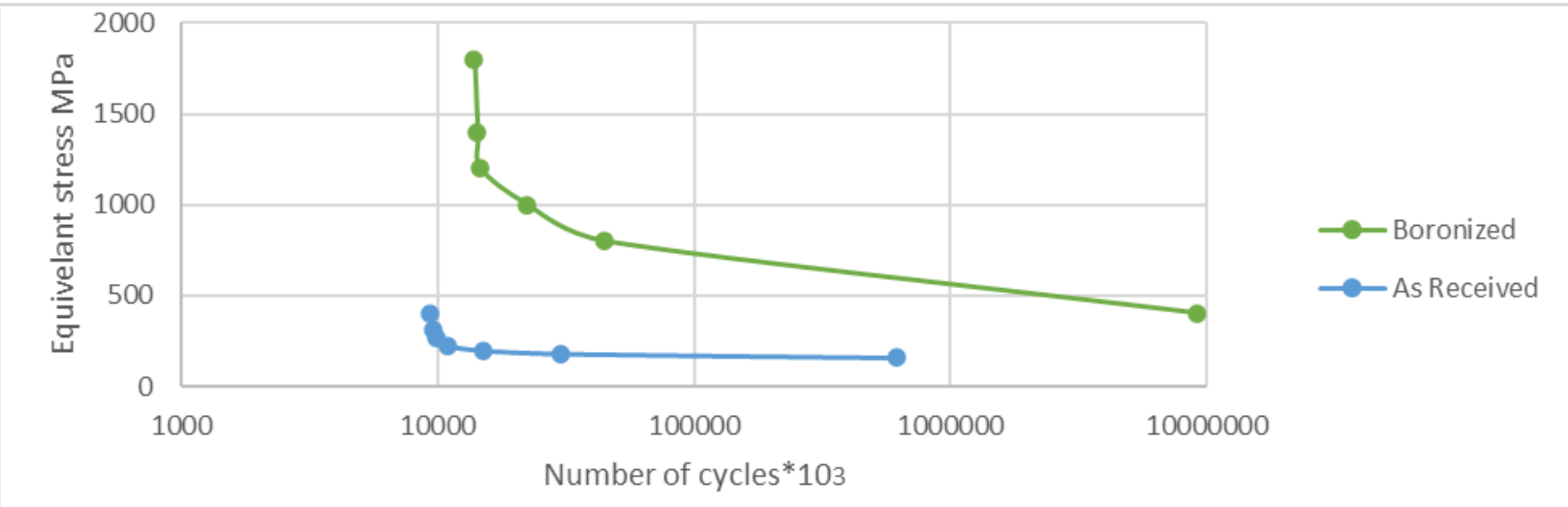

Figure 17. S-N curve of as received design B1 and Boronized sample Via ANSYS.

\section{CONCLUSIONS}

- 3-point repeated bending test is conducted for as received samples reveals softening with less strain to fracture simulate actual external stimuli of oil and gas piping.

- Optical microscopy reveals banding as a post-forming segregation mechanism.

- Pipping fracture mechanisms reveals (1) Localized micro-plasticity (grain boundary flow, beach marks, striations and persistent slip bands, void initiation) at the outer surface. (2) Crack initiation established via void coalescence. (3) Crack propagation almost $50 \mu \mathrm{m}$ spaced from outer surface. (4) Crack evolution as transvers cracking that may induce LBB. (5) Catastrophic failure with fracture surface reveal both PSB and rupture zone.

- Boronizing increases flexural stress, $\sigma_{\mathrm{f}}$ of AR sample, form $580 \mathrm{MPa}$ to $1214 \mathrm{MPa}(10$ minute Boronized sample) and $1390 \mathrm{MPa}$ (30 minute Boronized samples). Boronizing also increases surface hardness from $126 \mathrm{Hv}$ to $1792 \mathrm{Hv}$, and induce FGM.

- Fracture mechanisms established for boronized samples reveal that; (1) No clear micro plasticity recovered at the outer surface. (2) Most micro plasticity revealed far away from the most hardened surface in the bulk sample center. (3) Fracture mechanisms retarded from the most stresses outer surface to the least stressed center. (4) Crack initiation, crack propagation, crack evolution at the sample center just before failure. (5) In addition boronized samples reveal twinning and eliminate banding that start from 0.5 $\sigma_{u}$ to $0.6 \sigma_{u}$, aligned perpendicular to the outer surface instead of being parallel.

- Micro mechanical finite element modeling, ANSYS, established reveals the kinetic of boronizing that not only hinder plastic deformation in the outer hardened surface, but also hinder crack propagation, mitigate crack growth that extend service life.

- Stress-number of cycle to failure with boundary condition Fixed-fixed that induce circumferential deformation in both duct and header established to reveal the importance of boronizing that not only extend life but also increase endurance limit $\sigma_{\mathrm{e}}$ of as received from $\sigma_{\mathrm{e}}=157.5 \mathrm{MPa}$ at $6.1 \times 10^{5}$ cycles to $\sigma_{\mathrm{e}}$ of boronized $=405 \mathrm{MPa}$ at $9.23 \times 10^{6}$ cycles.

\section{REFERENCES}

[1] V.A. Carucci and R.T. Mueller, "Acoustically Induced Piping Vibration in High Capacity Pressure Reducing Systems," ASME 82-WA/PVP-8; 1982

[2] F. L. Eisinger, "Designing Piping Systems against Acoustically-Induced Structural Fatigue," ASME Journal of Pressure Vessel Technology, Vol. 119, 1997

[3] F. L. Eisinger, "Piping Systems Providing Minimal Acoustically-Induced Structural Vibration and Fatigue,’United States Patent, No. 5,711,350, 1998 
[4] F.L. Eisinger, "Acoustically Induced Structural Fatigue of Piping Systems," ASME Journal of Pressure Vessel Technology, Vol. 121, 1999

[5] F.L. Eisinger, "Acoustic Fatigue of Impellers of Rotating Machinery,” ASME Journal of Pressure Vessel Technology, Vol. 124, 2002

[6] NORSOK Standard L-002, Piping Design Layout and Stress Analysis, Rev. 3, July 2009

[8] Nishiguchi, M., Izuchi, H., Hayashi, I., and Minorikawa, G., "Investigation of Pipe Size Effect against AIV", Inter-Noise, 2012.

[9] Yuqing Liu, Philip Diwakar, and Dan Lin," A coustic Vibration Induced Fatigue in Welded Pipe Supports", Proceedings of the ASME 2017 Pressure Vessels and Piping Conference, July 16-20, 2017, Waikoloa, Hawaii, USA.

[10] Rudland, D., Wang, Y., and Wilkowski, G.; "Comparison of Crack-Opening Displacement Predictions for LBB Applications"; International Journal of Pressure Vessels and Piping; Vol 79; 2002: pp. 209-217.

[11] David. L. Rudland, and Craig Harrington," Development of the Extremely Low Probability of Rupture (xLPR) Code", 15th International Conference on Environmental Degradation, TMS (The Minerals, Metals \& Materials Society), 2011.

[12] Manobu M Tanaka, and Y. Kimura, "Fracture surface topography and fracture mechanism in austenitic SUS316 steel plates fatigued by repeated bending", Journal of Materials Science 41(10), January 2006.

[13] Manabu Tanaka, and Ryuichi Kato, "Fractal Analysis of Fracture Surfaces and Simulation of Fracture Process Using Fractal Dimension Maps in Stainless Steels Fatigued by Repeated Bending”, ISIJ International 52(9), January 2012.

[14] Bakr M. Rabeeh, "Ultra-Fast Brooding and Surface Hardening of Low Carbon Steel", TMS 2015 144th Annual Meeting \& Exhibition pp 1499-1506.

[15] Andrew Stetsko," The Nanocomposite Diffusion Coating of Details Prepared of Boriding", International Conference on Nanotechnology and Nanomaterials, NANO 2017: Nanochemistry, Biotechnology, Nanomaterials, and Their Applications pp 345356.

[16] Naiming Lin,Peng Zhou, Hongwei Zhou, Junwen Guo, Hongyan Zhang, Jiaojuan Zou, Yong Ma1, Pengju Han, Bin Tang, "Pack Boronizing of P110 Oil Casing Tube Steel to Combat Wear and Corrosion", Int. J. Electrochem. Sci., 10 (2015) $2694-2706$.

[17] Ricardo Andrés García-Léon, José Martínez-Trinidad, Iván Campos-Silva \& Wilbert Wong-Angel, "Mechanical characterization of the AISI 316L alloy exposed to boriding process", Revista DYNA, 87(213), pp. 34-41, April - June, 2020.

[18] Pablo A. Ruiz-Trabolsi, Julio Cesar Velázquez, Carlos Orozco-Álvarez, Rafael CarreraEspinoza, Jorge A. Yescas-Hernández, Noé Eliseo González-Arévalo and Enrique Hernández-Sánchez," Kinetics of the Boride Layers Obtained on AISI 1018 Steel by Considering the Amount of Matter Involved", Coatings 2021, 11, 259. 